\title{
Innovation, Investment, Enterprise: Generating Sustainable Livelihood at Grassroots through Honey Bee Philosophy
}

\author{
Anil K Gupta
}

W.P. No. 2012-06-04

June 2012

The main objective of the working paper series of the IIMA is to help faculty members, research staff and doctoral students to speedily share their research findings with professional colleagues and test their research findings at the pre-publication stage. IIMA is committed to maintain academic freedom. The opinion(s), view(s) and conclusion(s) expressed in the working paper are those of the authors and not that of IIMA.

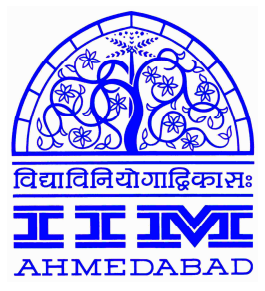

INDIAN INSTITUTE OF MANAGEMENT

AHMEDABAD-380 015

INDIA 


\title{
Innovation, Investment, Enterprise: Generating Sustainable Livelihood at Grassroots through Honey Bee Philosophy
}

\author{
Anil K Gupta
}

Professor, Indian Institute of Management Ahmedabad

\begin{abstract}
In memory of Dr. C.V. Seshadri, a maverick scientist and a social change agent, it is suggested that a new model for sustainable livelihoods is followed. The ex-ante and ex-post transaction costs of innovators, investors and entrepreneurs will have to be reduced if the new paradigm has to work. The benchmarking of unsolved problems of the society have to be linked with $R \& D$ and management institutions so that the societal tendency of living with problems indefinitely is contained. The innovation challenges are recommended to involve masses in solving persistent problems. A reference is made to challenge thrown open by Gandhiji in 1929 offering an award of Rs.1 lakh [worth about Rs.10 crores now] to improve the spinning wheel. In the post-independence India, we have never offered an award of this kind to solve any problem. I describe a framework for building value chain and a horizontal supply chain to reinforce in-situ value addition and people to people exchange and marketing system. Recalling the spread of Buddhism in the eastern Asia, more than 2000 years ago, it is stressed that culture cannot be made culprit. These very countries were heralding new models of economic growth. India has to likewise promote grassroots to global model reversing the current trend of globalization. A plea is also made for a Global Innovation Foundation premised on the philosophy and practice of Honey Bee Network.
\end{abstract}




\title{
Innovation, Investment, Enterprise: Generating Sustainable Livelihood at Grassroots through Honey Bee Philosophy ${ }^{1}$
}

\begin{abstract}
Anil K Gupta ${ }^{2}$
When an individual, institution, network or a society learns to live with a problem unsolved indefinitely, it ceases tobe a progressive and inclusive forward looking community. Indian society is going through a transformation when the traditional inertia is giving way and innovations are being recognized slowly and slowly as instruments of empowerment and change.
\end{abstract}

Dr. C.V. Seshadri was a maverick scientist and a social change agent. His social influence manifested in many forms, PPST was one of the sparks of the same. I had the opportunity to meet him and absorb his spirit way back in $80^{\prime}$ 's and early $90^{\prime}$ s. His belief that "Equity is Good Science" is something I share very strongly. The fact that he innovated so many technologies for larger social good distinguishes his contributions even more. His lighthearted contempt for armchair revolutionaries and scientists is something that I strongly empathise with. I am honoured to deliver this lecture in his memory and feel that the best tribute to him would be to invigorate our effort to engage with the young science and technology students and professionals to complete the unfinished agenda.

After more than two decades, Honey Bee Network could succeed in persuading the government to institutionalize a regular support to NIF (National Innovation Foundation) as a part of Department of Science and Technology, Government of India. The power of the network is apparent from the fact that almost 90 per cent or more of the ideas, innovations and traditional knowledge practices at grassroots are scouted through volunteers. The remaining entries are received at NIF. I will briefly summarize the journey and then describe a few lessons that follow from the journey for inclusive development. I firmly believe that the current decade declared as 'decade of innovation' by the Prime Minister and the

\footnotetext{
${ }^{1}$ Lecture delivered at Dr. C.V. Seshadri Memorial lecture at Chennai, $4{ }^{\text {th }}$ December 2010 and a much shorter version contributed to a book on Indian Innovations edited by Mr. L.K. Sharma.

${ }^{2}$ Professor, IIM Ahmedabad and Executive Vice Chair, National Innovation Foundation, and coordinator, SRISTI, Ahmedabad 380015, anilg@iimahd.ernet.in, anilgb@gmail.com
} 
President signifies a transformative phase of India's destiny. Many of us being very close to this situation may not realize how important this period would be in the history of the country after a few decades or a century. One of the major reasons is an aspirational revolution that is being experienced in different parts of the country.

There was creativity even in the past. There are numerous examples of outstanding excellence having been achieved in metallurgy, architecture, water management, health, food, etc., which have stood the test of the time. But, the fact remains that over a period of time, we internalized the constraints and generated a culture, which reinforced compromise, compliance and conformity rather than dissent, diversity and innovation. This habit could survive because of an accompanying culture of 'chaltahai', i.e., everything is all right. However, the current young generation is refusing to put up with such an attitude. Even in the earlier generation, those who had fortitudinous ability as evident from their innovations and off-beat approach to life and its challenges, are beginning to be recognized. Honey Bee Network has played a small role in bringing about change in the mindset.

Honey Bee Network implies basically four principles: Cross pollination of ideas in local languages, acknowledgement of individual and community creativity without making them anonymous, protecting their knowledge rights, and sharing the benefits in a fair and just manner accrued from value addition in the innovations or traditional knowledge. Accordingly, about 1,40,000 ideas, innovations and traditional knowledge practices [not all unique] have been mobilized from 545 districts of India. More than 90 per cent have been collected by the volunteers of Honey Bee Network while the remaining have come in response to the advertisements.

It all began with Honey Bee Network started in 1988-89 which led to establishment of SRISTI (Society for Research and Initiatives for Sustainable Technologies and Institutions) in 1993. As a follow up of an international conference on Creativity and Innovations at Grassroots held at IIMA during January 1997, Grassroots Innovation Augmentation Network [GIAN] was set up in collaboration with Gujarat Government. The purpose of GIAN was to reduce transaction costs of innovators, investors and entrepreneurs by linking them with each 
other. It was also the first attempt to provide micro venture capital support to grassroots innovations. NIF came about in 2000 with the help of Department of Science and Technology and has become grant-in-aid institution this year.

In 2003, based on an idea mooted by SRISTI in 1997 IIMA conference, a Micro Venture Innovation Fund [MVIF] was set up with the help of SIDBI. It has invested more than 2.5 crores in ideas and innovations by common people without collateral or guarantor. More than 60 per cent people have paid back and barring one or two cases, there is none who made profits and did not pay. More than 60 technological licenses have been given mainly to small companies and individual entrepreneurs with benefits going back to the innovators. In about two dozen cases, small entrepreneurs chose to license technologies after paying money even when patents had not been granted. This revealed to us an extraordinary ethical value on their part. If they had copied and commercialized, nothing could have been done legally. But, they chose to do otherwise. Probably the values of the network have created wider social capital.

Every summer and winter SRISTI organizes shodhyatras for last 13 years. We celebrate the creativity at its doorstep. The idea is to honour knowledge experts on the way to convey that outstanding traditional knowledge as well as contemporary innovations matter. Sometimes, when outsiders coming from far off places honour local institutions, individuals and other initiatives, the local respect for the same may also go up. It is part of the institution building effort in the country. It is easier to suggest that India should be a knowledge society but without recalibrating the worth of local knowledge such a transformation may not ever take place. We also organize biodiversity, recipe and idea competitions in the villages to demonstrate the spirit of excellence and collegiality. We try that those recipes which have some uncultivated plants as ingredients get special attention. In the wake of climate change, we might need new sources of food if the present one succumb to new diseases or pests. We have started preparations for any such catastrophe in the foreseeable future.

Many of the so-called weeds are actually rich source of nutrition. The inquisitiveness and 
the survival instincts of the poor people might actually hold the key to survival of humanity in future. Thus, attention to their knowledge need not be justified only on its own account and for potential help to the poor but also because it will provide ways of survival for the more privileged ones who have lost such an instinct.

We also take the blessings of centenarians on the way and try to learn from their life. Many times innovators are discovered serendipitously on the way. The biodiversity competitions provide a way of speeding up the knowledge transfer from grandparents to the grandchildren. It is an open book quiz where children can learn from anybody in the village about plants and their uses and bring their collection to the meeting. Sometimes the children who excel in this domain may not be very good in studies. Our society has not yet figured out a way of respecting multiple intelligences and thus enabling such children to grow as conservators of nature. This is a task still incomplete. The cultural creativity on the way is also celebrated. The purpose is to create markets for the creativity of unsung heroes and heroines of our society through e-commerce and other mechanisms.

\section{Implications for sustainable livelihoods:}

There are primarily four strategies, which I will advocate to policy makers, NGOs, NGIs and R\&D institutions that believe in inclusive innovations. The private sector willing to engage with knowledge rich, economically poor people can also contribute to these strategies in a viable manner.

1. Strengthening the technological and institutional basis of existing enterprises

2. Triggering innovation and knowledge based new enterprises

3. Benchmarking the unsolved problems of society and linking them with R\&D and management institutions

4. Building value chain and horizontal supply chain to reinforce in-situ value addition and people to people exchange and marketing 


\section{Strengthening the technological and institutional basis of existing enterprises}

Large number of existing enterprises instead of becoming more remunerative over time, start losing money. That is how we explain widespread poverty in agriculture and rural sector. When a vast majority generates a very small share of GDP and that too growing at a very small rate if at all, the marginalization of their socio-economic system becomes evident. One of the ways in which these enterprises can be made viable is by looking at the viability of household portfolios [Gupta $1981^{3}$ ] rather than each enterprise separately. Second way would be infusion of science and technology to improve productivity. Third approach can be improvement in the scope and scale of activities to make negotiating power of the producers felt in the market place. Fourth dimension of this process can be recalibrating the institutional framework so that the role of common property institutions, so critical for sustainability, can be appreciated. The role of other collective institutions has been neglected a great deal in the literature and by the practitioners. In our anxiety to treat each individual as an independent decision maker, we have unnecessarily given away the advantages of social, cultural and ethical capital in our everyday life. Let me illustrate some of these dimensions. We all know that in dry regions the role of craft, livestock, trees and grasses is far more important than just the crops. Even within the crops, the role of fodder and fibre is more important than the grain. And yet, the focus of public policy and many NGO interventions remains focused on improving crop productivity. Given the market and climatic fluctuations, a great deal of effort generates a very minor pay off. If the portfolio of activities is taken into account and flexibility and malleability of choices is enhanced, the household and the communities will be able to make better choices. If there is too much rain, as it was this year in some parts of the country, the monsoon crop may not mature early and the pay off may be limited. Farmers developed a practice in Haryana of harvesting the millet crop as fodder and focus on timely sowing out winter pulse crops on residual moisture to get much higher economic returns. The fodder of the pulse crops such as chickpea acts as a spice for livestock like camel and cattle. If you try to look for literature on the fodder quality of chickpea plant and leaves, you may not be able to find much

\footnotetext{
${ }^{3}$ Gupta, Anil K, 1981, "Viable Projects for Unviable Farmers - An Action Research Enquiry into the structure and Processes of Rural Poverty in Arid Regions, Symposium on Rural Development in South Asia, IUAES Inter Congress, Amsterdam
} 
knowledge base. This is true despite large number of national and international research institutions working on the subject. The breeding objectives of crops and trees would also get modified. Once the SEVA team in Madurai took me to neem farms and showed how the local people figured out the productivity of trees by looking at the orientation of the cracks on the bark. If it was upward, it was perhaps better compared to horizontal orientation [Vivekanandan, personal communication, 1995]. Such insights are seldom collected and rarely disseminated. Thus, a farmer growing tree crop nourishes or looks after even less productive trees. The value of the wood, seed, creepers growing on trees [as medicinal plant], bark, leaves, etc., imply a very different approach to viability. Not many farmers realize that the system of storing neem seed itself could affect the proportion of active ingredients and the oil. How many farmers and NGOs monitor the patent database to find out what are the new technologies being developed on each of the base resources. Large number of patents expire or are abandoned by the innovators every year. This valuable knowledge base is open access and can be used and modified as one wishes. Even if this one lesson can be taken home by everybody in the audience, I would feel happy and something would change in the lives of millions of people.

In most of the rainfed regions, the agro biodiversity is very rich. In the current context of consumer preference and market conventions, the demand for local varieties is very limited. If we characterize the nutritional and medicinal properties of some of these varieties, a new market can be generated without any other change in the system. If organic labeling is done where possible, additional value may be added. The food processing is one of the fastest growing industries in the country. It is well known that when incomes increase, the share of processed food also increases in the consumption basket. But, very little of this share is harnessed by the poor communities. It was alright for Prahalad to see the fortune at the base of economic pyramid by targeting them as consumers. But, how much can they consume, if their purchasing power is not expanded. It is in this context that livelihood programme should measure its effectiveness by identifying this parameter as an indicator.

The opportunities for generating livelihoods though knowledge and culture based enterprises remains to be properly exploited. It is only in India that we can classify 250 
million people as 'unskilled' under the National Rural Employment Guarantee Programme [NREGP]. There is nothing more dehumanizing than devaluing the skills, knowledge and value in which poor people are rich. If someone can sing very well or perform or make sculptures, drawing on the wall or excel in any other field of art, culture or crafts, should such a person be asked to break stones and dig earth. One way in which we can create market for such people is to put small videos, audios of their skill on the web and create market opportunities for them. A young child of Tamilian parents from Madurai in USA or anywhere else in the world may like to hear stories in the local dialect used by his/her grandmother. Putting such stories on the net will enrich the cultural world of the children and their parents might not mind paying a few cents every download, which can go to the storytellers. A very simple proof of the concept has been created at www.sristi.org/cultural but much more remains to be done. There is no reason why livelihood programmes at different levels in the country should focus on only labour aspect of people's life rather than skill and knowledge aspects. The paradigm has to change and India has to take its own people and their strengths more seriously.

\section{Triggering innovation and knowledge based new enterprises}

Honey Bee Network has mobilized tens of thousands of ideas, traditional knowledge and innovations from all sectors, segments, social spaces of our society.

\section{Transaction costs involved in linking innovations, investment and enterprise}

The ex-ante transaction costs have four components: (i) searching information (ii) finding supplier, (iii) negotiating contract and (iv) drawing up the contract. The expost transaction costs include (i) monitoring and compliance, (ii) side payments, i.e., concessions which can make the contract enforceable through modified inducements/ discounts, (iii) resolution of conflicts if any and (iv) redrawing the contract if none of the above help in going ahead with the contract. While designing the eco system, the institutions and actors have to reduce their transaction costs if any mediating platform has to have legitimacy. 
i. Searching information: How do traditional knowledge holders or grassroots innovators find out the potential applications of their knowledge for which a third party may have some use and thus the need to enter into negotiation for possible negotiation of contract and share benefits. Likewise, the entrepreneurs who want to set up businesses around innovative products and services have to find out about the potential leads. They may or may not be internet savvy. In some cases, they may not even be educated. The method of searching information has to be compatible with the existing knowledge, capacity and willingness to pursue on the part of seeker of information. At the same time, the format of information and the language can also make a difference in influencing the reduction of transaction costs. The potential investor may not know both the entrepreneur or the innovator. The available information may not confer sufficient faith in his mind to motivate him to invest. How would then such investors develop partnership with the innovators and/or entrepreneurs. This cost cannot be met only by providing information on the web and that too in English language. The access to multimedia, multi language databases may make it possible for people to learn from each other and also with other stakeholders. In the case of herbal knowledge, the transaction costs of the potential investors, entrepreneurs, and R\&D players in seeking knowledge about the local communities with scientific names of the plants is enormously high. In the absence of scientific names (which can only be ascribed after taxonomic authentication), the modern scientific institutions, drug, dye, nutriceutical companies may not be able to make offers of possible cooperation.

Tracking usurpation of one's knowledge rights:

Local communities and individual innovators also need to track the usurpation of their knowledge by unauthorized IP seekers. They will have to have access and the ability to scan the patent applications around the world, interpret and then inform themselves and the patent offices about any suspected violation ${ }^{4}$.

\footnotetext{
${ }^{4}$ USPTO has started recently a discussion forum around the patent applications and under certain condition, any prior art revealed by any one on the web can be taken into account while examining that application. But there is
} 
Otherwise they will remain dependent on the benevolence of the state or other civil society organization. The bringing of their knowledge into public domain without their authorization by national and international scholars and institutions has been the single most important instrument of exploitation and unfair treatment of their knowledge rights (no research council in developing world or developed countries has yet characterized such a behaviour on the part of the scholars as inadmissible and unethical conduct). In the absence of such a reform as mentioned later in the paper, 'lawful' and 'rightful' disclosure is the only option. The publication of people's knowledge and thus bringing it in public domain reduces the transaction costs of potential users in western and educated segments of eastern society. Their search costs goes down without conferring any advantage to the local communities and grassroots innovators. However, providing synoptic information is extremely useful and can generate tremendous queries for the knowledge holder. NIF received queries for various grassroots innovations from more than 55 countries entirely because it shared the synoptic information on the web. Therefore, we should balance the advantage of open source, multi language databases with the disadvantage of disclosing unique knowledge. In the case of multi language database, put up by SRISTI on its website, about 5000 innovations/traditional knowledge practices were put up in public domain so as to generate wider interest in this knowledge system. It is also expected that various intermediary users will share this resource with local communities. The search cost of the communities will not go down otherwise. This is one of the reasons why SRISTI organizes along with the NIF shodhyatras [learning walks] twice a year so that existing knowledge base can be shared with

no doubt, it will improve the quality of the applications. This innovation is particularly important for those developing countries which do not have enough examiners like India. But the substantive issue is, how to enable communities and local innovators to read these patents put up for discussion in USA and published in other countries, How much public is public domain after all, and for whom? Will information in English be accessible to the local communities not knowing English language? How should translation wiki, as was suggested by a student in Margaret Chong's class at Seattle Law School, be created for worldwide access to different language communities. May be the students worldwide can translate patents apparently based on traditional knowledge or biodiversity in different languages one page a week and soon, we will have enough resources for tracking the unauthorised IP. There is another way to tackle this problem. I have suggested that every patent applicant should declare that all the knowledge disclosed or used while making claims made in their application have been obtained 'lawfully and rightfully'. 
local communities at their doorstep. This is a very costly way of diffusing knowledge though it has its own advantages in terms of cultural and ethical impact it has on the learners' values. An initiative of Honey Bee on mobile is under discussion with some telecom service providers so that almost 500 million mobile phone users can be reached depending upon their need and preferences by the Honey Bee Network. It is a paradox that such an initiative could not be taken off for want of resources for more than five to six years.

ii. Finding suppliers: Having found the sources of information, one has to find providers of information, services and other support systems. For a local healer or conservator of genetic resources to take a sample of their material to a public or private sector R\&D lab to get it analysed for potential negotiations is almost well neigh impossible. It is important to create capacity so that they can deal with the knowledge providing, processing and managing institutions at their own terms. For an innovator, to find supplier of facilities for fabrication of machineries, testing, design, packaging and marketing and distribution is not easy. That is why a lot of grassroots innovations remain undeveloped and localized. The cost of finding innovators have been reduced drastically for all stakeholders because of Honey Bee Network's contribution over last two decades. NIF maintains a database and is able to connect people just for a call. The mobile revolution has meant that farmers from different parts of country and the world can call and get information. In due course, once we are able to generate resource for Honey Bee on mobile, we will be able to make lot of the information retrievable through voice protocol without human mediation. The supplier of authentic information, commodities or services may not become apparent or obvious while searching information. Somebody has to authenticate information before a lay person can rely on it. Transaction costs involved in finding supplier should not be confused with just making a website or a database. There is a whole lot of vouchsafing to be done before a bit of information becomes worth engaging with. Similarly, for an investor or entrepreneur or a corporation, finding the right kind of innovation, meeting their specifications may require prior prior art search and benchmarking. 
iii. Having found a supplier or potential user of their knowledge, they have to negotiate a contract and use a combination of IP and/or contractual instruments as a basis for negotiation. The tension between individual and collective knowledge, organizing proper representation and nomination for negotiation and having internal as well as external negotiations are other dimensions that come into play. Negotiations between a rural innovator and an urban entrepreneur or investor can involve a whole range of ethical issues of informed consent, capacity to negotiate, honest brokering, etc. SRISTI, GIAN and now NIF help innovators in this regard when opportunities for licensing their technologies arise. There have been cases where entrepreneurs have licensed technologies for which patents were not even granted. The entrepreneurs paid money because they appreciated the spirit of the negotiating platform, i.e., Honey Bee Network. Therefore, negotiation is not just a matter of finalizing the terms of exchange but also involves influencing the ethical framework in which stronger party does not necessarily take advantage of the weaker party.

iv. Drawing up the contract: To be able to exercise prior informed consent, and then arrive at reasonable terms of agreement which are acceptable within the community and as well as to the negotiating partner involves tremendous complexity, cost and resources. Without meeting these costs and enabling the communities, the contracts may remain asymmetrical and sometimes difficult to enforce. The language of the contract may not always be comprehensible to school drop out innovators. Under such conditions, the responsibility of Honey Bee Network becomes very critical. Some of the interesting dimensions of the contract negotiated so far in the last 15-20 years are:

a. The first contract SRISTI entered into with a company involved pooling of public domain traditional knowledge and licensed with a small upfront payment. 
b. Licensing of the rights to manufacture and market on district basis. This was perhaps the first time in the country when a technology was licensed to three small entrepreneurs for right to sell in earmarked districts. The fee was hardly USD 500 to 1000 depending upon number of districts. This can help in democratizing the technological innovation and at the same time bring small actor into the market who may otherwise be deterred by the complexity of negotiations and terms. There was no patent granted on tilting bullock cart in this case. However, media attention and awards to the innovator influenced the market for technology.

c. The licensing to entrepreneurs on exclusive basis with the condition that if they did not sell pre-specified number of products in a year [on which royalty depends], then the license would become nonexclusive.

d. Incorporating the privilege of marketing the value added product developed by the entrepreneur in his own district. In addition to the royalty and upfront payment, the innovator also gets dealership for a district.

e. The licensee is enabled to access funds for adding value to the product.

There are many other conditions, which have been negotiated to safeguard the interest of the innovator including the right to revert the license if the licensee did not commercialise a technology within a given period.

v. Having entered into a contract, keeping track of the licensing and sub-licensing of technologies by the primary contractor becomes an obligation of the communities. It is possible that the contracting party, in this case, a company or a state agency, may not work the licensed IP from the communities directly. They may sub-license it to a third party who may generate revenues, which may or may not be shared. It is important to keep track of such a process. The 
enforcement of the conditions therefore requires tremendously important skills and capacities have to be built for acquiring and using those skills. There have been cases where the licensee did not follow all the terms diligently. So far, the Network has avoided legal recourse for settling such problems. However, it is very clear that in the absence of any power to enforce, a small grassroots innovator may feel handicapped.

vi. Side payments: It is not always possible for communities or individual grassroots innovators to wait for benefits to accrue and share. Upfront benefit sharing may be necessary. Such concessions may have to be negotiated. Some times offering concessions beyond the terms of contract generates confidence. Recently, a firm, Matrix Bioscience, to which SRISTI licensed twelve herbal products developed in its lab gave the name and photographs/sketches of the innovators on the package of these products. This was a side inducement so to say. Likewise, innovators can offer some additional leads if the deal on the earlier one goes well to induce the contracting parties go beyond the terms of the contract. The opportunity exists on both the sides for making terms of contract mutually favourable by offering concessions, discounts or other considerations if the agreed terms of contract are not generating desirable outcomes.

vii. Conflict management: During the benefit sharing process, conflicts may arise. Such situations require capacity building of the community of the innovators to settle the disputes in an efficient manner, without damaging their interests and welfare. Hence, the capacity of the community/innovators to negotiate, identify the right platforms, engage public interest lawyers and supporters becomes crucial to achieving the ends of justice. Here the role of Network and NIF becomes very critical. There have been cases where innovators entered into contract with a company on their own and later when the terms were not upheld, they sought the help of NIF. Sometimes, local collaborators in their anxiety to help the innovators fast, may take recourse to short-circuiting the 
negotiation and contractual process with best of the intentions. But, given their lack of experience, the innovators may suffer and consider the Network responsible. It is a matter where careful attention has to be paid by all the stakeholders to avoid conflicts to go out of hand. So far, the policy of the Network has been to avoid acrimonious exchanges and thus try to use the power of persuasion. The results have been satisfactory by and large.

viii. Renegotiating the contract: If despite all the persuasion, the existing terms don't work and conflicts cannot be resolved satisfactorily, the renegotiation with the attendant costs is the only alternative. In some cases, this may even be desirable ${ }^{5}$.

\section{Benchmarking the unsolved problems of society and linking them with R\&D and management institutions}

Our generation betrayed the trust of the society by learning to live with a large number of problems unsolved, indefinitely. Thus, if women experienced tremendous drudgery in picking leaves from tea bush, pulling water from the well using pulley without stopping mechanism, transplanted paddy by keeping their feet in water for fortnight or a month, collected fuel wood and grass on hill slopes and in forests over long distance, etc., we did not bother. The top institutions of science and technology also did not bother. The NGOs and various other social organisations also learnt to live with them. The way out is to benchmark all such problems during production process, post harvest, food processing, forest product collection and processing, transporting and treating drinking water, crafts, livestock management and other non-farm activities. While doing so, we might come across some innovations. But in many cases, our experience shows that women's problems have often been neglected even by the male grassroots innovators.

\footnotetext{
5 Anil K Gupta, Prateek Gautam, Ramesh Patel, Hema Patel, Purshotham Patel, Chetan Patel, Alka Patel, Nirmal Sahay, Riya Sinha, P.Vivekanandan, Balaram Sahu, Sunda Ram, Vipin Kumar, Nitin Maurya, Mahesh Patel, Chinzah Lalmunzuala, Vivek Kumar, T.N.Prakash, Rajeev Pandey, Ganesham Pogula, Jahoor Ahmed, Kishore Kalita and other members of Honey Bee Network, "Values in vogue: Institutional pathways for sustaining grassroots innovations for creating public goods", Nov 2010, Second Policy brief, IDRC, Canada supported project Grassroots Innovations for Inclusive Development( GRIID), SRISTI (Society for Research and Initiatives for Sustainable Technologies and Institutions), Ahmedabad, www.sristi.org
} 
This neglect of innovations for and by women is not peculiar to India. Autumn Stanley in her book on "Mothers and Daughters of Invention", a product of 13 year long study of US patents over 200 years found similar neglect. Following steps can help us address this problem once for all and then create a platform for ongoing solutions to second or third generation emerging problems. While doing so, we may recall what Gandhiji had done in 1929 when he announced a global competition to redesign charkha to reduce drudgery of the people ${ }^{6}$.

AkhilaBharatiyaCharkhaaSangh Workers' Samiti has decided to organise this Contest for inventors and engineers all over the world that if they could come up with a Charkha or a SamyuktaYantra which - for making the thread and cloth, that satisfies the following criterion - shall be awarded a Prize money of 1 Lakh Rupees or 7700 pounds.

The Criterion:

1. Charkha must be light-weighted, easy to move, and it should be in such a way so as to be operated using either hand or one's leg - in a natural way in the rural cottages of India.

2. Charkha must be in such a way that a lady shall be able to work with it for 8 hours at a stretch without great effort put in.

3. Either Charkhas must have a build to accommodate the use of a puni (used to make handspun cloth)or along with the charkha there must be a way to handspun cloth.

4. On working with the charkha for 8 hours at a continuous stretch - it should result in 12 to 20 numbers of 16000 feet (1 gaj?) yarn.

5. The machine should be so designed such that it costs no more than Rs. 150 in producing it in India only.

\footnotetext{
${ }^{6}$ Empathetic innovations: Connections across boundaries, to be published in a book entitled, "Timeless Legend of India, Gandhi" [Ed.] Dr. R. A. Mashelkar in commemoration of 30 years of Gandhi National Memorial Society, Pune, 2010, IIMA WP No.2010-09-02, September 2010, 43-57
} 
6. The machine should be strong and well-made and with time-to-time servicing it should be capable of running for at least 20 years without any stopping. Servicing of the machine should not cost much and every year not more than $5 \%$ of the cost of the machine that year shall be needed for servicing.

7. All those taking part in this contest, may - with their own input costs and expenses send their machines to Sabarmati Ashram before or not later than 30th October, 1930. In case the machines satisfy the criterion mentioned - then the inventor/designer can patent it on his name to protect their rights on them.But, if they wish to become eligible to win the prize money of the contest, then the designer shall have to transfer the rights of the patent to Indian Charkha Sangh Council.

8. The Judges for the Contest shall be KhadiPratishtan's Sri Satish Chandra Das Gupta, BardoliSwarajya Ashram's Technical Director Sri LakshmidasPurushottam and Tiruchengonduu Gandhi Ashram's Director Sri Chakravarthy Rajagopalachari. In case there is no consensus amongst the judges on the winner - Gandhiji's decision shall be the final one. In case of Gandhiji's absence Akhil Bharat Charkha SanghMantri Sri Shankar Laal Banker shall be the final decision-maker.

All questions and queries may be addressed to Mantri, Akhil Bharat Charkha Sangh, Mirzapur, Ahmedabad. Dated: 24th July 1929. Shankarlal Banker.

After more than eight decades, Indian government or philanthropists have yet to announce a similar award for solving problems of disadvantaged people of our country. So much for inclusion. The present value of this award is more than Rs.10 crores. We don't have even a one crore prize for solving problems which have held back the progress of our society for thousands of years. SRISTI has supported a platform designed with the help of students led by HiranmayMahantalast year, viz., www.techpedia.in. It already has more than 100,000 engineering projects pursued by around 350,000 final year students from over 500 colleges. There are options at this site of problems in search of solutionsand innovations in search of augmentation. Dozens of student teams from IIT Mumbai have already volunteered to take up augmentation challenge this year. Slowly and slowly, we can mobilize a large part of 10 
lacs students who graduate every year from engineering colleges. Ministry of Human Resource Development or AICTE or UGC might continue to neglect this important task of connecting real life problems of our society with the technology youth of our country. There are many other advantages of such a portal for promoting originality, innovation, connection with MSME, etc., which I have discussed at my blog, www.sristi.org/anilg. I will restrict here to what we can do for improving livelihoods in the near term by engaging with the youth.

Step one: Post problems, bottlenecks, inefficiencies, pain points in the existing technological practices pursued by the poor. If possible, one can attach videos, sketches, diagrams, material properties, etc., as well. Through the linkage Honey Bee Network has with international groups like Engineers for Change, or Engineers beyond Borders and American Society of Mechanical Engineering, we can mobilize intellectual resources from around the world.

Step two: Students submit the synopses i.e., the planned strategy for solving each problem. Even if 500 students show interest in one problem, we should not bother. Let there be lot of redundancy and a small support of say Rs. $25,000-50,000 /=$ may be given in two installments to the students whose synopses are found worthwhile with an expenditure of Rs.50 lacs we can support 100 or more student teams to crack one problem.

Step three: We create an online collaborative platform to trigger healthy competition and also collaboration across teams to generate good solutions. In some cases, we may protect the IPRs of the teams with the understanding that these will be transferred to either NIF or SRISTI or some such body responsible for managing the process. The protection of IPRs will in such cases be of defensive nature, i.e., to prevent others from monopolizing.

Step four: It is possible that in one cycle, none of the teams may come out with final product. Using a kho-kho model, we can create an innovation relay and selected projects are put forward for further follow up work in the next cycle. By pooling the best practices and getting feedback from users through multimedia, multi language platforms, we can 
certainly get the final product. Mentors from private and public sectors with professional background as entrepreneurs, academics, fabricators or mechanics may be mobilized to guide the student teams. Around 2000 mentors have already registered at National Mentor Network at www.techpedia.in.

Step five: Attractive awards will be given to the best teams or even those who contributed important building blocks of the final solution or to the most glorious failure to encourage risk taking. These awards can be given at the biennial Presidential award function of NIF so that the country celebrates the victory over persistent inertia in a befitting manner.

Step six: Entrepreneurs are invited to manufacture the final designs of technologies reducing drudgery, improving efficiency and generating employment. Risk capital fund is used to underwrite the risk of such entrepreneurs. Ideally, a distributed manufacturing strategy should be encouraged so that in a decentralized and deconcentrated manner, location-specific adaptations evolve.

It is my firm belief that with all our acts of commission and omission, the future leaders of our country will not grow with the same sense of patience that we have had with inefficiency, inertia and indifference towards the problems of disadvantaged people.

\section{Building value chain and horizontal supply chain to reinforce in-situ value addition and people to people exchange and marketing}

Adding value for building horizontal and vertical supply chains: The reason languages evolve is to articulate multiple meanings [some intersecting partially or completely and others nonoverlapping], which help in expanding the scope for imagination. It is such an imagination or even speculation, which triggers experimentation in some cases. If meanings could not be expanded, then new possibilities would be difficult to conceive. If a language has a word for flying object, viman, thousands of years ago, it has created a possibility to conceive a flying object. But, if such an object does not get developed, then it was not because language lacked the capability to conceive or speculate but because of other institutional or 
cultural reasons. Value addition in local or external resources is important for improving efficiency of resource use, conservation, augmentation and dissemination of service or products to others. Formal R\&D institutions perform this function within their mandates and try to expand the potential for value addition in different sectors to meet various social and industrial needs. This R\&D process is not restricted to public or private sector only but can also be extended to cooperatives, labour and workers unions and informal associations of farmers, pastoralists, artisans, etc. In many cases, individuals on their own through their own resources also do research or experimentation and sometimes innovations. While support system for formal sector is well developed though even that can be improved a great deal, the one for informal sector is weak and non-existent in majority of the countries. It is ironic because most societies facing one form or other of rural protest, insurgency, social unrest or violence realize that some of it can be traced to persistent poverty, unemployment and lack of public support for meeting basic needs. And yet, the indifference continues. The paradox is that this indifference, conceptually, leaves lot of space for local experimentation even if sub-optimally and devoid of opportunities for validation through blending with formal science and technology. It is this space that we have explored in the Honey Bee Network and wish to trigger new institutional designs, which can augment ability to experiment and innovate at individual and community level. The horizontal supply chains have existed from time immemorial through weekly markets in the most interior regions whether relying on barter, cash or gift economies. But, with inroads made by modern markets and other institutions, these chains have become weaker. The perception of utility of products and services provided by local experts or entrepreneurs has also changed over time due to media exposure or deliberate public policy. A bone setter who might be a better expert than an institutional medical facility might not get as much attention of the local communities in some areas as she might deserve. This may have nothing to do with her expertise. Local products in various functional domains can be developed by pooling inputs from local villages. The value added products can be packaged for short distance and short period consumption. Such a strategy will strengthen local small loop economies and reduce carbon footprints, economise on energy consumption and reduce entropy. Some of the raw materials for vertical supply chains also are provided by the similar regions. But, devoid of any stake in 
the supply chain, the people mainly perform the task of collection of raw materials as labourers. Since no in-situ value addition takes place, due to inflationary and other pressures, their real wage rates often go down instead of increasing. While the growth takes place in the value added sector, these regions and people therein remain at the lowest end of the value chain. Their knowledge rights are not protected and their ability to get royalty from the exploitation of these potential rights remains unexplored. Policy gaps both in horizontal and vertical supply chains are many and require systematic attention if the capabilities of local communities for sustainable resource use and improve livelihood have to be significantly augmented. The social unrest will be otherwise an inevitable consequence ${ }^{7}$.

There are many more ways in which we can make the mission sustainable livelihoods a vibrant programme involving the young and the motivated people. I don't think we should ever argue that public programmes being bureaucratically governed have to inevitably follow an old archaic envelope. They can and they must come out of this envelope to diffuse into a more participatory, open and collaborative public policy - implementation framework. The private sector and civil society organisations can follow equally archaic processes and systems. They need to reform and restructure as much as public systems have to do. The knowledge intensive approaches discussed in this paper can help link innovations, enterprise and investments from all around in a focused manner, but with sufficiently fuzzy boundaries. The accountability should be high but structural designs should be loose. This is a subject for separate discussion.

Honey Bee Network has tried to develop a g2G model i.e., grassroots to global. Indian model of development cannot be designed to serve only Indian needs. We should be inclusive enough to share our insights, innovations and institutional capacity with other countries which are willing to engage with us. The countries that wish to lead always share

\footnotetext{
${ }^{7}$ Gupta, Anil K., "Policy gaps for promoting green grassroots innovations and traditional knowledge in developing countries: learning from Indian experience”, April 2010, First Policy brief, IDRC, Canada supported project Grassroots Innovations for Inclusive Development( GRIID), SRISTI (Society for Research and Initiatives for Sustainable Technologies and Institutions), Ahmedabad, www.sristi.org
} 
and involve other cultures in their growth processes. It is not surprising that countries which are likely to decline in future have already started becoming more introvert and protectionist in their outlook. More than 2000 years ago, India shared the Buddhist philosophy far and wide. Those countries which learnt from this philosophy have shifted the centre of the world eastward. We have to take the right cues. Our culture need not become a culprit. We have to select the right metaphors and meanings to transform our vision for future.

A global innovation foundation based on the philosophy and the practice of Honey Bee Network may not be too far. If creative people around the world get opportunities to craft their own world, one would not have to invent policies for making society compassionate, collaborative and accommodative of various social segments. It is the failure to nurture grassroots creative potential that has fuelled so much of social anomie. May be peace through inclusive innovations and participatory institutions is the next mantra of development. 